Claude Guérin
Jordi Mancebo

\title{
Prone positioning and neuromuscular blocking agents are part of standard care in severe ARDS patients: yes
}

Received: 8 June 2015

Accepted: 9 June 2015

Published online: 23 September 2015

(C) Springer-Verlag Berlin Heidelberg and ESICM 2015

For contrasting viewpoints, please go to doi:

10.1007/s00134-015-4040-6 and doi:10.1007/s00134-015-4043-3.

\section{Guérin}

Réanimation Médicale, Hôpital de la Croix Rousse, Hospices Civils de Lyon, Université de Lyon, Lyon, France

C. Guérin

INSERM 955 Eq13, Créteil, France

J. Mancebo (®)

Servei de Medicina Intensiva, Hospital de Sant Pau,

C. St Quintí 89, 08041 Barcelona, Spain

e-mail: jmancebo@santpau.cat

The panel of experts who developed the new Berlin definition for acute respiratory distress syndrome (ARDS) recommended customizing ventilator strategies and adjunct therapies according to the level of oxygenation [1, $2]$. The definition states that low tidal volumes $\left(V_{\mathrm{T}}\right)$ must be applied at all levels of severity. The experts favored the use of positive end-expiratory pressure (PEEP) in all ARDS categories, but at varying levels: low or moderate PEEP in mild ARDS, and high PEEP in severe ARDS.

In severe ARDS, defined as $\mathrm{PaO}_{2} / \mathrm{F}_{\mathrm{I}} \mathrm{O}_{2}$ of less than $100 \mathrm{mmHg}$ under PEEP of at least $5 \mathrm{cmH}_{2} \mathrm{O}$, the experts also recommended prone position (PP) and use of neuromuscular blocking agents (NMBA). They based their $P P$ recommendation on the results of meta-analyses $[1,2]$, which were further confirmed by a multicenter trial on severe ARDS, the PROSEVA trial [3]. In this trial, ARDS severity was defined as $\mathrm{PaO}_{2} / \mathrm{F}_{\mathrm{I}} \mathrm{O}_{2}$ no greater than $150 \mathrm{mmHg}$ with PEEP of at least $5 \mathrm{cmH}_{2} \mathrm{O}, \mathrm{F}_{\mathrm{I}} \mathrm{O}_{2}$ of at least 0.6 with an average $V_{\mathrm{T}}$ of $6.1 \mathrm{ml} / \mathrm{kg}$ predicted body weight. The PROSEVA trial showed a major decrease in mortality rate at 28 and 90 days after randomization in patients treated with PP. The experts recommendation of using NMBA was based on a randomized placebo-controlled trial, the ACURASYS trial [4]. In this trial, ARDS severity was defined as $\mathrm{PaO}_{2} / \mathrm{F}_{\mathrm{I}} \mathrm{O}_{2}$ no greater than $150 \mathrm{mmHg}$ with PEEP of at least $5 \mathrm{cmH}_{2} \mathrm{O}$ and with an average $V_{\mathrm{T}}$ of $6.5 \mathrm{ml} / \mathrm{kg}$ predicted body weight. The ACURASYS trial showed a significant reduction in the hazard ratio for death at 90 days in the NMBA group as compared to the placebo group, after adjusting for confounding variables $\left(\mathrm{PaO}_{2} / \mathrm{F}_{\mathrm{I}} \mathrm{O}_{2}\right.$ ratio, SAPS II, and endinspiratory plateau airway pressure levels). Patients with the lowest $\mathrm{PaO}_{2} / \mathrm{F}_{\mathrm{I}} \mathrm{O}_{2}$ (defined as a threshold of $120 \mathrm{mmHg}$ in the Cox model) made up two-thirds of the population and showed the highest reduction in mortality rate when NMBA were administered.

There are three main reasons for PP and NMBA forming part of standard care in severe ARDS patients: pathophysiological rationale, clinical benefit, and safety. Regarding the pathophysiological background, PP and NMBA achieve the two main goals of invasive mechanical ventilation in ARDS, namely to maintain safe gas exchange (which very often markedly improves in PP) and to prevent ventilator-induced lung injury [5]. In PP, as compared with supine position, transpulmonary pressure and ventilation are more homogeneously distributed throughout the lung [6]. Overall lung stress and overdistension are minimized $[7,8]$, lung volumes increase, and biotrauma and ventilatorinduced lung injury are decreased $[9,10]$. By resting the respiratory muscles, NMBA can avoid high regional transpulmonary pressures, and hence induce less regional volutrauma or biotrauma [11]. In the ACURASYS trial, the rate of pneumothorax [4] was significantly lower in the NMBA group than in the placebo group. In addition, the amount of lung inflammation was significantly lower in the NMBA group than in the placebo group in a previous 
randomized trial involving 36 patients [12]. The use of NMBA can also avoid dangerous respiratory entrainment ("reverse-triggered" breaths) [13] and pendelluft phenomena [14]. Reverse-triggered breaths may increase end-inspiratory lung volume and hence overinflation. Pendelluft phenomena occur in spontaneously triggered breaths: at the very beginning of inspiration, the non-dependent regions deflate while the dependent regions are overstretched. Pendelluft magnifies cyclic recruitmentderecruitment of unstable, dependent alveoli. Finally, the use of NMBA avoids a number of asynchronies such as double-triggering and double inspirations, and also wasted inspiratory efforts during the expiratory phase. When double-triggering and double inspirations are abolished by NMBA, breath-stacking phenomena and excessive endinspiratory lung volume will, most likely, disappear. The absence of wasted inspiratory efforts avoids pliometric or eccentric contractions of the respiratory muscles that may generate ventilator-induced diaphragmatic injury.

Among the numerous interventions that have been tested in ARDS over the years, only three have proven beneficial to patient survival: low $V_{\mathrm{T}}$, PP, and NMBA. These interventions, however, do not change the clinical course of the underlying disease leading to ARDS. Hence, the most likely interpretation for the success of these three interventions is that the overall supportive strategy in ARDS is useful to prevent the harmful effects of mechanical ventilation: high tidal volumes generating overdistension, suboptimal recruitment of collapsed units generating cyclic opening and closing of alveoli, and abnormal patient-ventilator interactions impeding the delivery of "protective" ventilator breaths.

How patients were selected and treated in the ACURASYS and the PROSEVA trials is a highly relevant aspect in relation to the beneficial effects of NMBA and PP. These two trials showed almost identical 28-day mortality rates in the control groups, $33.3 \%$ in the former and $32.8 \%$ in the latter $[5,6]$. Both trials enrolled patients with confirmed ARDS: the median time from ARDS diagnosis to inclusion was $16 \mathrm{~h}$ in the ACURASYS trial, and the mean time from intubation to randomization was close to $32 \mathrm{~h}$ in the PROSEVA trial. The way the interventions were applied should also be considered. NMBA and PP were both applied early, with a specific strategy, at adequate doses, and for a sufficient duration. NMBA were administered for $48 \mathrm{~h}$, and PP was administered for sessions over 17 consecutive hours. In the case of PP, sessions were continued until predetermined criteria of oxygenation improvement were met.

Additional pathophysiological benefits may operate in PP. Since oxygenation is markedly improved, this may help to reduce PEEP. If high PEEP levels are decreased, then the right ventricle will be unloaded, thus helping to prevent acute cor pulmonale, which has been shown to occur in up to $50 \%$ of ARDS patients $[15,16]$. Furthermore, in ARDS patients who have a preload reserve while in the supine position, the change to PP has been shown to increase cardiac output [17].

But can we balance all these benefits with risk and safety issues? The safety of proning has long been a concern for caregivers because of the risk of serious complications such as intravascular line dislodgment or endotracheal tube removal during the procedure. However, the PROSEVA trial was conducted in experienced centers and the rate of airway-related complications did not differ significantly between the supine and the prone position groups. In a previous randomized trial, also conducted in experienced centers, more than 700 proning procedures were performed and only 28 complications were observed [18]. These data indicate that the maneuver is safe and has a minimal risk profile when performed by skilled personnel and in well-selected patients. Intensivists have long been reluctant to use NMBA because these molecules were implicated in ICU-acquired neuromuscular weakness. This was the case particularly when NMBA had been used in conjunction with glucocorticoids in patients with status asthmaticus. Data to support such claims however, is, at best, poor [19, 20]. Importantly, in the ACURASYS trial, $16 \%$ of patients in the NMBA

Table 1 Risk-benefit balance of using neuromuscular blocking agents (NMBA) and prone position (PP) in severe ARDS

\begin{tabular}{lll}
\hline & NMBA & PP \\
\hline Improvement in oxygenation & Yes & Yes \\
Prevention of ventilator-induced lung injury & Not proven & Yes \\
Pneumothorax rate reduction & Yes & No \\
Biotrauma modulation & Yes & Yes \\
Patient-ventilator asynchrony reduction & Yes & No \\
More homogeneous strain/stress distribution & Not proven & Yes \\
Hemodynamic preservation/improvement & No & Yes \\
Muscle weakness & No & No \\
Endotracheal tube dislodgement/kinking & No & Yes, but risk minimized \\
& & in trained teams \\
Withdrawal of indwelling catheters & No & Yes, but risk minimized \\
$\quad$ and pressure sores & in trained teams \\
Mortality reduction & Yes & Yes \\
Price & Expensive & Cheap, but requires motivated \\
& & and skilled caregivers \\
\hline
\end{tabular}


group and $23 \%$ in the control group received corticosteroids for ARDS, and $39 \%$ of patients in the NMBA group and $45 \%$ of patients in the control group also received corticosteroids for septic shock. In spite of the simultaneous use of corticosteroids and NMBA, the British Medical Research Council score for muscle strength assessed at 3 months after enrollment was remarkably similar in both groups. Table 1 summarizes the benefitrisk profile of PP and NMBA administration.
In summary, there is currently sufficient, consistent, and reproducible data to confirm the overall usefulness of early prone positioning in severe ARDS and to consider it as part of routine care in these patients. Data on NMBA are perhaps less impressive. However, their use in conjunction with PP is justified in view of the strong pathophysiological rationale, the remarkably low rate of side effects, and the potential risks of not using them, especially when facing abnormal patient-ventilator interactions.

\section{References}

1. Sud S, Friedrich JO, Taccone P, Polli F, Adhikari NKJ, Latini R, Pesenti A, Guérin C, Mancebo J, Curley MAQ (2010) Prone ventilation reduces mortality in patients with acute respiratory failure and severe hypoxemia: systematic review and meta-analysis. Intensive Care Med 36:585-599

2. Gattinoni L, Carlesso E, Taccone $\mathrm{P}$, Polli F, Guerin C, Mancebo J (2010) Prone positioning improves survival in severe ARDS: a pathophysiologic review and individual patient metaanalysis. Minerva Anestesiol 76:448-454

3. Guerin C, Reignier J, Richard JC, Beuret P, Gacouin A, Boulain T, Mercier E, Badet M, Mercat A, Baudin O, Clavel M, Chatellier D, Jaber S, Rosselli S, Mancebo J, Sirodot M, Hilbert G, Bengler C, Richecoeur J, Gainnier M, Bayle F, Bourdin G, Leray V, Girard R, Baboi L, Ayzac L, PROSEVA Study Group (2013) Prone positioning in severe acute respiratory distress syndrome. N Engl J Med 368:2159-2168

4. Papazian L, Forel JM, Gacouin A, Penot-Ragon C, Perrin G, Loundou A, Jaber S, Arnal JM, Perez D, Seghboyan JM, Constantin JM, Courant P, Lefrant JY, Guerin C, Prat G, Morange S, Roch A (2010) Neuromuscular blockers in early acute respiratory distress syndrome. N Engl J Med 363:1107-1116

5. Slutsky AS, Ranieri VM (2013) Ventilator-induced lung injury. N Engl J Med 369:2126-2136

6. Mutoh T, Guest RJ, Lamm WJ, Albert RK (1992) Prone position alters the effect of volume overload on regional pleural pressures and improves hypoxemia in pigs in vivo. Am Rev Respir Dis 146:300-306
7. Mentzelopoulos SD, Roussos C, Zakynthinos SG (2005) Prone position reduces lung stress and strain in severe acute respiratory distress syndrome. Eur Respir J 25:534-544

8. Cornejo RA, Diaz JC, Tobar EA, Bruhn AR, Ramos CA, Gonzalez RA, Repetto CA, Romero CM, Galvez LR, Llanos O, Arellano DH, Neira WR, Diaz GA, Zamorano AJ, Pereira GL (2013) Effects of prone positioning on lung protection in patients with acute respiratory distress syndrome. Am J Respir Crit Care Med 188:440-448

9. Papazian L, Gainnier M, Marin V, Donati S, Arnal JM, Demory D, Roch A, Forel JM, Bongrand P, Bregeon F, Sainty JM (2005) Comparison of prone positioning and high-frequency oscillatory ventilation in patients with acute respiratory distress syndrome. Crit Care Med 33:2162-2171

10. Park MS, He Q, Edwards MG, Sergew A, Riches DW, Albert RK, Douglas IS (2012) Mitogen-activated protein kinase phosphatase-1 modulates regional effects of injurious mechanical ventilation in rodent lungs. Am J Respir Crit Care Med 186:72-81

11. Slutsky AS (2010) Neuromuscular blocking agents in ARDS. N Engl J Med 363:1176-1180

12. Forel JM, Roch A, Marin V, Michelet P, Demory D, Blache JL, Perrin G, Gainnier M, Bongrand P, Papazian L (2006) Neuromuscular blocking agents decrease inflammatory response in patients presenting with acute respiratory distress syndrome. Crit Care Med 34:2749-2757

13. Akoumianaki E, Lyazidi A, Rey N, Matamis D, Perez-Martinez N, Giraud R, Mancebo J, Brochard L, Marie Richard JC (2013) Mechanical ventilation-induced reverse-triggered breaths: a frequently unrecognized form of neuromechanical coupling. Chest 143:927-938
14. Yoshida T, Torsani V, Gomes S, De Santis RR, Beraldo MA, Costa EL, Tucci MR, Zin WA, Kavanagh BP, Amato MB (2013) Spontaneous effort causes occult pendelluft during mechanical ventilation. Am J Respir Crit Care Med 188:1420-1427

15. Vieillard-Baron A, Charron C, Caille V, Belliard G, Page B, Jardin F (2007) Prone positioning unloads the right ventricle in severe acute respiratory distress syndrome. Chest 132:1440-1446

16. Boissier F, Katsahian S, Razazi K, Thille AW, Roche-Campo F, Leon R, Vivier E, Brochard L, Vieillard-Baron A, Brun-Buisson C, Mekontso Dessap A (2013) Prevalence and prognosis of cor pulmonale during protective ventilation for acute respiratory distress syndrome. Intensive Care Med 39:1725-1733

17. Jozwiak M, Teboul JL, Anguel N, Persichini R, Silva S, Chemla D, Richard C, Monnet X (2013) Beneficial hemodynamic effects of prone positioning in patients with acute respiratory distress syndrome. Am J Respir Crit Care Med 188:1428-1433

18. Mancebo J, Fernandez R, Blanch L, Rialp G, Gordo F, Ferrer M, Rodriguez F, Garro P, Ricart P, Vallverdu I, Gich I, Castano J, Saura P, Dominguez G, Bonet A, Albert RK (2006) A multicenter trial of prolonged prone ventilation in severe acute respiratory distress syndrome. Am J Respir Crit Care Med 173:1233-1239

19. De Jonghe B, Sharshar T, Lefaucheur JP, Authier FJ, Durand-Zaleski I, Boussarsar M, Cerf C, Renaud E, Mesrati F, Carlet J, Raphael JC, Outin H, Bastuji-Garin S (2002) Paresis acquired in the intensive care unit: a prospective multicenter study. JAMA 288:2859-2867

20. Kress JP, Hall JB (2014) ICU-acquired weakness and recovery from critical illness. N Engl J Med 371:287-288 